\title{
Effect of Joule-Heating Treatment on the Microstructure and Physical Properties of 16-Stranded Compressed Copper Wires
}

\author{
Jin-Ju Choi, Byoungyong Im, Yubin Kang, and Dae-Geun Kim ${ }^{\dagger}$ \\ Institute for Advanced Engineering (IAE), Materials Science and Chemical Engineering Center, Yongin 17180, Republic of Korea
}

\begin{abstract}
Compressed wires are produced by cross-sectionally compressing stranded conductors, which results in a smaller conductor diameter. This also leads to a lower weight wire, because a thinner external insulated coating can be used, compared to the low-voltage wires typically used in automobiles. However, a post production heat treatment of the compressed wires is required because plastic deformation occurs during compression after drawing the wires. In this study, the work hardening of stranded compressed copper wires was controlled by Joule-heating, and the resulting changes in microstructure, mechanical, and electrical properties after various annealing voltages $(0,25,27,31,35$, and $39 \mathrm{~V})$ were observed. The results confirmed that as the annealing voltage increased from 0 to $31 \mathrm{~V}$, the anisotropic deformation texture with a <111> orientation as the main component was reduced, and micrograins were generated throughout the stranded wires via recrystallization. At an annealing voltage above $31 \mathrm{~V}$, the grains grew to be more than twice as large as those before heat treatment. At an annealing voltage of $31 \mathrm{~V}$ these structural changes contribute to the elongation increase of the compressed wires to $28.34 \%$, and an improvement in electrical resistance to $145.85 \mathrm{~m} \Omega$.
\end{abstract}

(Received July 7 2021; Accepted August 23, 2021)

Keywords: compressed wire, joule-heating, annealing voltage, recrystallization

\section{Introduction}

Electric wires are key components in automobiles and have a range of uses, from power lines to start the engine, to sensors to check tire pressure. In the automobile industry, as the number of electronic components continues to increase to provide safety and convenience, the number of wires is also proportionally growing [1]. This increase in the number of wires also leads to an increase in vehicle weight. For a typical mid-sized car, the wire weight is over $20 \mathrm{~kg}$ [2], and it increases with the number of electronic components, particularly in electric powered cars. As regulations on carbon dioxide emissions are applied throughout the world, it has become essential to improve fuel efficiency by reducing automobile weight. This has produced growing interest in reducing the weight and diameter of wires.

Compressed wires have a reduced conductor diameter

- 최진주 - 강유빈: 연구원, 임병용: 선임연구원, 김대근: 책임연구원

*Corresponding Author: Dae-Geun Kim

[Tel: +82-31-330-7419, E-mail: dgkim@iae.re.kr]

Copyright (c) The Korean Institute of Metals and Materials obtained by cross-sectionally compressing stranded conductors $[3,4]$. This leads to weight reduction because these wires require less external insulating coating compared to the lowvoltage wires typically used in automobiles. Unfortunately, plastic deformation occurs in the stranded wires during the compression process, and additional work hardening occurs after the wire drawing. In conventional wires, the residual stress and microstructure can be controlled via heat treatment during the wire drawing process. However, for compressed wires, an additional heat treatment is required to control the work hardening caused by compression after the formation of the stranded conductor.

The plastic deformation induced by the formation of compressed wires can cause slip and the accumulation of dislocations inside the stranded wires. These accumulated dislocations act as driving forces of recrystallization, affecting the microstructure during heat treatment [5-8]. This is important because the size and distribution of grains after heat treatment are factors that determine the mechanical and electrical properties of the stranded conductor [5,9-12]. To address this, it's necessary to analyze the correlation between 
heat treatment condition and microstructure.

Joule-heating by supplying a current to wire is known to be an effective method for the heat treatment of thin wire [1319]. Because copper has a small heat capacity $\left(0.385 \mathrm{~J} / \mathrm{g}^{\circ} \mathrm{C}\right)$, the temperature of small-scale copper wire can be easily increased by passing a current [20]. It has been reported that normal copper wires can be softened by Joule-heating [19, 20], and that grains grow faster than with heat treatment using a conventional furnace [13,20]. Tohmyoh et al. [20] reported that during the Joule- heating of copper microwires, yield strength decreased as the grain size increased. The yield strength of untreated copper microwire was $311 \mathrm{MPa}$, and it decreased to $190 \mathrm{MPa}$ after heat treatment at $150{ }^{\circ} \mathrm{C}$. Rudolf et al. [21] confirmed that when a constant current was applied during the tensile testing of copper wire, tensile strength and yield strength decreased as the current increased.

However, unlike research on normal copper wire, studies on the Joule-heating of compressed copper wires are rarely reported, and the effect of plastic deformation during compression on mechanical and electrical properties needs to be studied.

In the present study, heat treatment was performed using Joule-heating to control the mechanical and electrical properties of compressed copper wires. The effect of heat treatment on the microstructure, mechanical and electrical properties of the stranded wires was also investigated. To this end, 16-stranded compressed wires were manufactured, and the stranded conductors were subjected to heat treatment under various annealing voltages. In addition, the elongation, tensile strength, and electrical resistance of the stranded wires were measured. The microstructure characteristics of the wires were then examined by electron backscatter diffraction (EBSD). Finally, the heat treatment behavior of the compressed wires was studied based on the annealing voltage.

\section{Experimental Methods}

The compressed wires were produced with a 16-stranded wire structure, as shown in Figure 1. The diameter of each wire was $0.29 \mathrm{~mm}$ and made of high-purity copper (purity $>99.9 \%$ ). The compressed wires were fabricated in two steps, a first compression to form the core and a subsequent

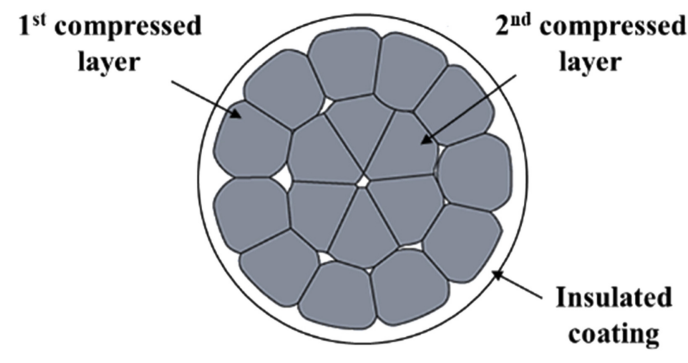

Fig. 1. Schematic of 16-stranded compressed wire.

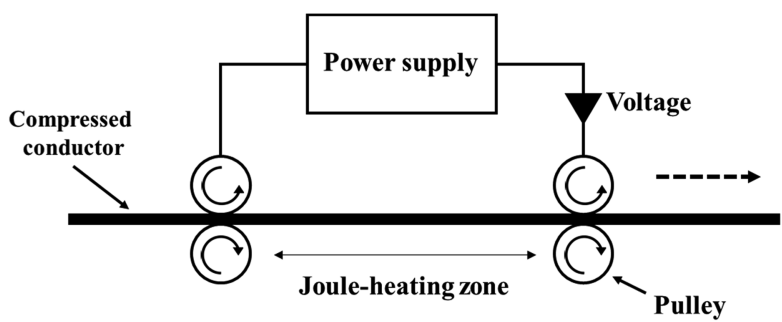

Fig. 2. Schematic of Joule-heating system.

compression to form the outer layer.

After the second compression, Joule-heating was performed as the heat treatment to remove the residual stress accumulated in the material during wire drawing and compression, and to control the uniformity of the structure, as shown in Figure 2. Heat treatment was performed in the following order: pay-off, annealing, cooling, drying, and take-up. After annealing, the conductor was quenched in cooling water, followed by drying to remove the residual moisture on the conductor surface; the heat treatment was completed after take-up.

Table 1 shows the heat treatment conditions for the 16stranded compressed wires used in this study. The annealing voltage was varied from 25 to $39 \mathrm{~V}$, while the drying voltage $(13 \mathrm{~V})$ was kept constant for all specimens. Heat treatment was performed at a constant rate of $700 \mathrm{~m} / \mathrm{min}$ during the entire process from pay-off to take-up.

To examine the changes in the mechanical and electrical properties of the stranded compressed wires with the annealing voltage, the elongation, tensile strength, and electrical resistance were analyzed, and the microstructural changes were observed using electron backscatter diffraction (EBSD). The elongation and tensile strength were measured with a universal testing machine (DTU-900MHN, DAEKYUNG 
Table 1. Heat treatment conditions for the stranded compressed wires

\begin{tabular}{lccc}
\hline & $\begin{array}{c}\text { Annealing } \\
\text { voltage (V) }\end{array}$ & $\begin{array}{c}\text { Drying } \\
\text { voltage (V) }\end{array}$ & $\begin{array}{c}\text { Velocity } \\
(\mathrm{m} / \mathrm{min})\end{array}$ \\
\hline As-received & - & - & - \\
Specimen 1 & 25 & 13 & 700 \\
Specimen 2 & 27 & 13 & 700 \\
Specimen 3 & 31 & 13 & 700 \\
Specimen 4 & 35 & 13 & 700 \\
Specimen 5 & 39 & 13 & 700 \\
\hline
\end{tabular}

TECH). The test was conducted at a gauge length of $250 \mathrm{~mm}$ and a tensile deformation rate of $30 \mathrm{~mm} / \mathrm{min}$. The electrical resistance of the compressed wires was measured using a multimeter (RM3544, HIOKI) after connecting both ends of the wires to a clamp (2754, YOKOGAWA). For microstructure analysis, specimens were made by cutting and mechanically polishing the stranded wires along the length, and the center of the cross section was observed by EBSD (JSM-F100, JEOL).

\section{Results and Discussion}

The elongation, tensile strength, and electric resistance of the stranded compressed wires as a function of the annealing voltage are listed in Table 2. Before heat treatment, the specimens exhibited an average elongation of $3.03 \%$, tensile strength of $469.73 \mathrm{MPa}$, and electric resistance of $151.63 \mathrm{~m} \Omega$ At an annealing voltage of $25 \mathrm{~V}$, the elongation, tensile strength, and electric resistance were $10.3 \%, 251.87 \mathrm{MPa}$, and $147.01 \mathrm{~m} \Omega$, respectively. Compared to the specimens without heat treatment, the elongation increased by approximately $239.93 \%$, while the tensile strength and

Table 2. Mechanical and electrical properties of compressed wires according to the annealing voltage

\begin{tabular}{lccc}
\hline & $\begin{array}{c}\text { Elongation } \\
(\%)\end{array}$ & $\begin{array}{c}\text { Tensile strength } \\
(\mathrm{MPa})\end{array}$ & $\begin{array}{c}\text { Electric } \\
\text { resistance }(\mathrm{m} \Omega)\end{array}$ \\
\hline As-received & 3.03 & 469.73 & 151.63 \\
Specimen 1 & 10.30 & 251.87 & 147.00 \\
Specimen 2 & 20.14 & 231.79 & 146.35 \\
Specimen 3 & 28.34 & 220.07 & 145.85 \\
Specimen 4 & 28.03 & 224.08 & 145.07 \\
Specimen 5 & 27.17 & 219.70 & 144.93 \\
\hline
\end{tabular}

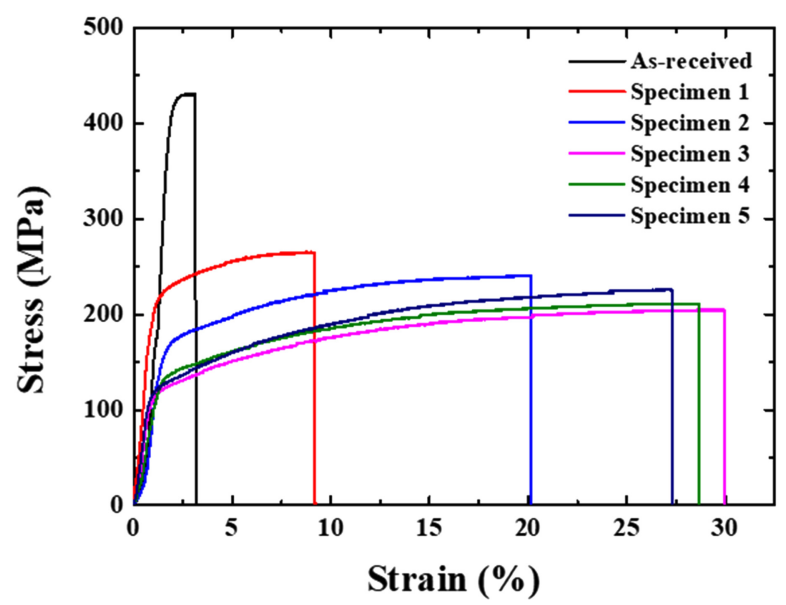

Fig. 3. Stress-strain curves of the compressed wire according to annealing voltage

electrical resistance decreased by $46.38 \%$ and $3.05 \%$, respectively. This tendency increased as the annealing voltage increased. At an annealing voltage of $31 \mathrm{~V}$, the elongation, tensile strength, and electrical resistance were $28.34 \%$, $220.07 \mathrm{MPa}$, and $145.85 \mathrm{~m} \Omega$ respectively. When the annealing voltage exceeded $31 \mathrm{~V}$, the tensile strength and resistance tended to converge while the elongation decreased slightly.

The stress-strain curves of the compressed wires according to annealing voltage are presented in Figure 3. Before heat treatment, work hardening was hardly observed. After reaching the yield point, fracture occurred without necking, and showed a low work hardening exponent. After heat treatment, the yield strength and tensile strength decreased while the work hardening region increased. It can be seen that the work hardening exponent increased until an annealing voltage of $31 \mathrm{~V}$, and tended to converge after $31 \mathrm{~V}$.

The EBSD inverse pole figure (IPF) map analysis results for the compressed wires with annealing voltage are shown in Figure 4. Before heat treatment, an anisotropic structure subjected to tensile deformation along the wire drawing direction can be observed; the $<111>$ orientation is the main component. The average grain size was $3.17 \mu \mathrm{m}$, and relatively fine grains were observed after wire drawing and compression.

In the specimen subjected to an annealing voltage of $25 \mathrm{~V}$, micrograins generated by recrystallization can be observed. Recrystallization is evident on the exterior of the wire, but 


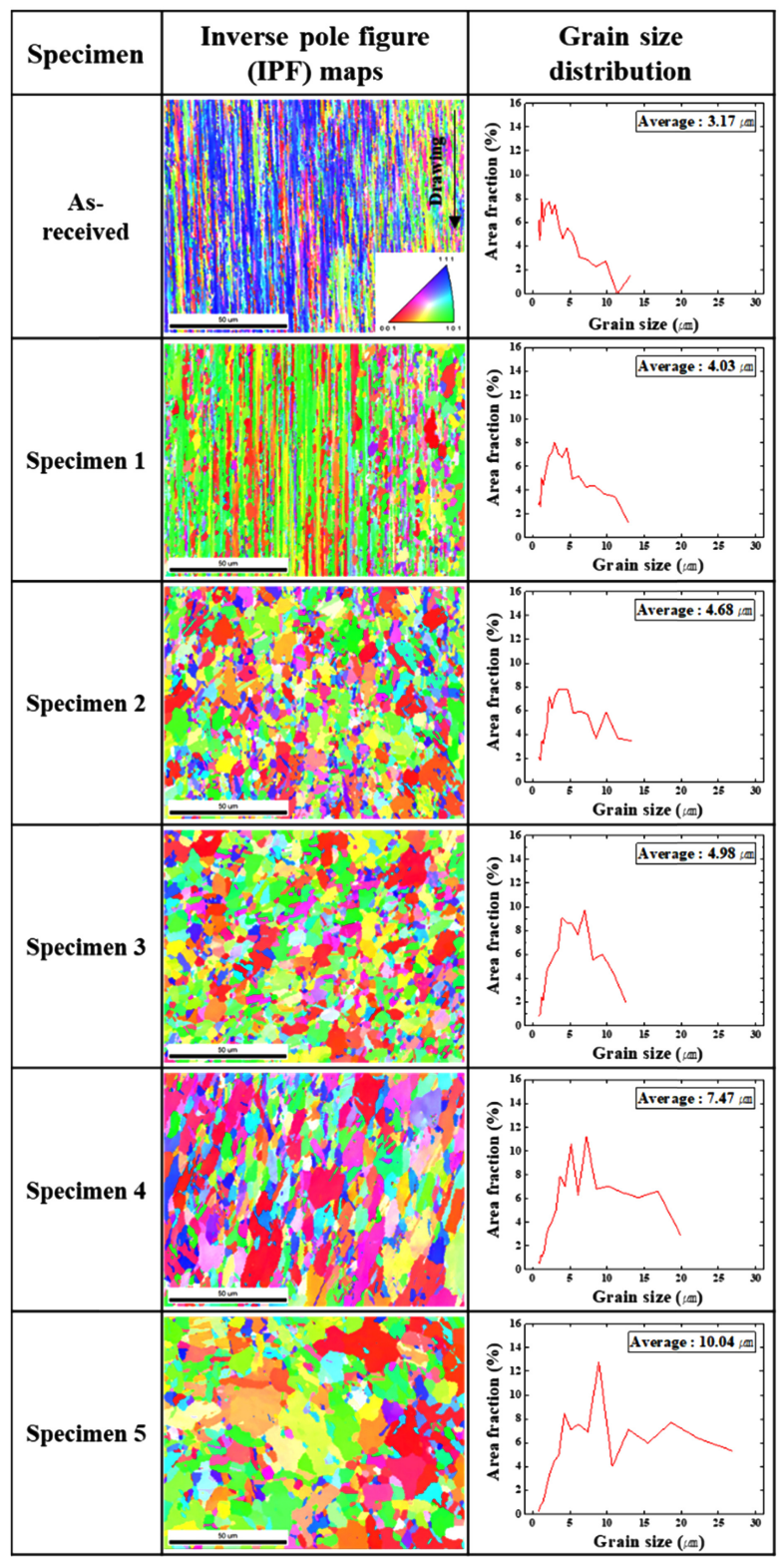

Fig. 4. EBSD IPF patterns and grain size of the compressed wires according to the annealing voltage.

the central region of the wire still exhibits structural deformation along the wire drawing direction. In the specimen subjected to an annealing voltage of $27 \mathrm{~V}$, deformation along the wire drawing direction is absent, and a recrystallized structure is observed across the entire wire, including the center.

The recrystallization microstructure was found to become more homogeneous as the annealing voltage increased. Furthermore, the size of the grains increased when the annealing voltage was $31 \mathrm{~V}$ or higher, and it reached $10.04 \mu \mathrm{m}$ at $39 \mathrm{~V}$.

Figure 5 shows the EBSD grain boundary (GB) map and kernel average misorientation (KAM) analysis results for the compressed wires with annealing voltages of $0,25,31,39 \mathrm{~V}$. In the GB map analysis, several low-angle grain boundaries could be observed before heat treatment. This tendency was also confirmed for the $25 \mathrm{~V}$ annealed specimen. The lowangle grain boundary is concentrated in the central region of the wire. As the annealing voltage increased, the low-angle grain boundaries decreased, while the fraction of high-angle grain boundaries increased. In the specimen subjected to an annealing voltage of $31 \mathrm{~V}$, the fraction of high-angle grain boundaries larger than $15^{\circ}$ was 0.795 , and increased to 0.824 with an annealing voltage of $39 \mathrm{~V}$. In the KAM map results, it was observed that the dislocation density decreased as the annealing voltage increased. In the specimen with an annealing voltage of $25 \mathrm{~V}$, the fraction of misorientation between $0^{\circ}$ to $1^{\circ}$ increased from the exterior of the wire. As the annealing voltage increased, misorientation between $0^{\circ}$ to $1^{\circ}$ was observed across the entire wire, and it was confirmed that the dislocation density decreased due to the recrystallization.

It is known that a deformation texture with a $<111>$ orientation as the main component develops in copper with a face-centered cubic structure after the wire drawing process $[5,22-25]$. The same tendency was observed in the compressed wires, where the exterior of the stranded conductor was compressed, as shown in Figure 4. In general, texture subjected to tensile deformation in the wire drawing direction degrades elongation and electrical properties, as well as the dislocations accumulated during wire drawing and compression. Hence, the specimens before heat treatment exhibited lower elongation and electrical properties than the heat-treated specimens.

When heat treatment was performed using an annealing voltage of $25 \mathrm{~V}$, the texture with the $<111>$ orientation in the wire drawing direction disappeared and recrystallization with $<110>$ and $<100>$ orientations as the main components occurred. In particular, the $<100>$ orientation develops to maximize the release of deformation energy accumulated by dislocations, when grains with the $<111>$ orientation are recrystallized by heat treatment $[5-7,26]$.

As the anisotropic structure in the wire drawing direction 


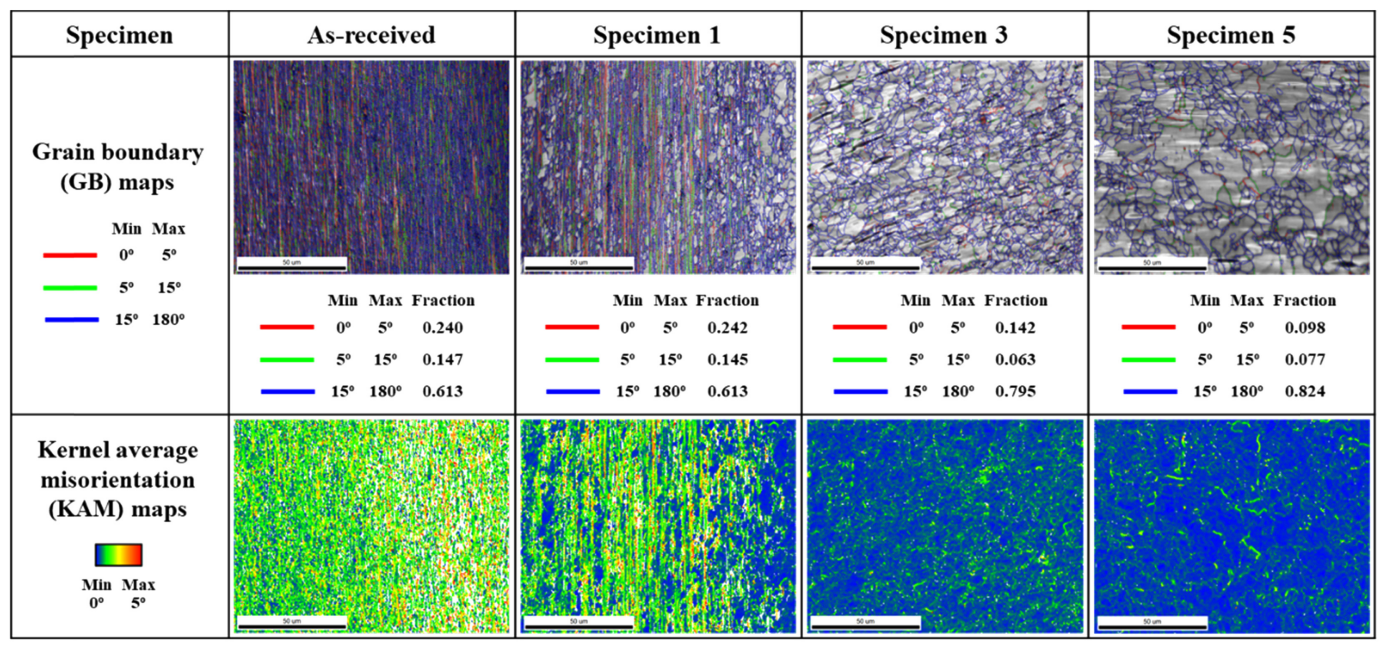

Fig. 5. EBSD GB map and KAM map analysis results of the compressed wires according to the annealing voltage

and the dislocation density decreased, the tensile strength decreased by approximately $217.86 \mathrm{MPa}$, but the elongation increased to more than twice that of the specimens before heat treatment. The change in the mechanical and electrical properties continued up to an annealing voltage of $31 \mathrm{~V}$, at which point recrystallization occurred throughout the compressed wires. When the specimens were subjected to annealing voltages of 27 and $31 \mathrm{~V}$, the deformation caused by wire drawing and compression disappeared and isotropic recrystallized structures were generated, indicating that the elongation and electrical properties improved compared to the specimens subjected to heat treatment at $25 \mathrm{~V}$.

In particular, the specimens subjected to an annealing voltage of $31 \mathrm{~V}$ exhibited approximately $8.2 \%$ higher elongation than those subjected to $27 \mathrm{~V}$. This appears to be because most of the dislocations accumulated by wire drawing and compression were removed, and the grain size distribution became uniform at an annealing voltage of $31 \mathrm{~V}$. When the annealing voltage exceeded $31 \mathrm{~V}$, the grain size increased to more than twice the size of grains present before heat treatment. No further improvement in mechanical or electrical properties was observed as the grain growth stage approached.

\section{Conclusions}

In this study, Joule-heating was performed as a heat treatment after the formation of the stranded conductor, to control the work hardening of 16-stranded compressed copper wires. In addition, the effect of the annealing voltage on the microstructure, mechanical, and electrical properties of the wires was investigated.

1) The mechanical and electrical properties of the compressed wires without heat treatment were as follows: an elongation of $3.03 \%$, tensile strength of $469.73 \mathrm{MPa}$, and electrical resistance of $151.63 \mathrm{~m} \Omega$. Work hardening characteristics with low elongation and high electrical resistance were observed because of the anisotropic structure in the drawing direction, and the accumulation of dislocations during wire drawing and compression.

2) Following heat treatment by Joule-heating, a reduction in anisotropic deformation texture with the $<111>$ orientation as the main component, and the generation of micrograins in the compressed wires by recrystallization, were observed. These structural changes continued until the annealing voltage reached $31 \mathrm{~V}$, after which the elongation improved to $28.34 \%$ and electrical resistance was reduced to $145.85 \mathrm{~m} \Omega$.

3) When the annealing voltage exceeded $31 \mathrm{~V}$, the generated grains grew to more than twice the size of those before heat treatment. Additional changes in dislocation density or recrystallization were hardly observed, and the mechanical and electrical properties showed a tendency to converge.

4) Considering the changes in microstructure, mechanical and electrical properties, it was determined that an annealing voltage was up to $31 \mathrm{~V}$ for the recrystallization of the compressed wires used in this study, and that the optimal 
parameter for controlling the work hardening was an annealing voltage of $31 \mathrm{~V}$.

When a stranded compressed wire conductor is formed, heat treatment is required to control the work hardening caused by compression. Considering convenience and productivity, a continuous heat treatment method such as Joule-heating is an appropriate process. However, the wires move with high speed during processing, it is difficult to accurately measure the heat treatment temperature and time. It is also hard to precisely control the mechanical and electrical properties. Compressed wires are highly useful in various industries for weight reduction, and controlling their mechanical and electrical properties is important to ensure the proper characteristics in the final product. Further research on process parameters such as heat treatment rate, and so on, is required.

\section{Acknowledgements}

This study was supported by the Energy Efficiency \& Resources of the Korea Institute of Energy Technology Evaluation and Planning (KETEP) grant funded by the Korea Government Ministry of Knowledge Economy (No. 20182020109920).

\section{References}

1. Y. Otsuka, T. Nishikawa, J. Yoshimoto, and Y. Akasofu, SAE Int. J. Passeng. Cars - Electron. Electr. Syst. 5, 486 (2012).

2. S. Koch, \& H. Antrekowitsch, BHMBerg-und Hüttenmännische Monatshefte 152, 62 (2007).

3. M. Kondo and M. Yoshimura, US patent, 7528319 (2009).

4. T. Kamata, US patent, 6576844 (2003).

5. H. Park, S. H. Kim, S. J. Kim, and H. J. Lee, Korean J. Met. Mater. 56, 861 (2018).

6. D. N. Lee, Texture and Related Phenomena, 2nd Edition, 280, The Korean Institute of Metals and Materials, Seoul (2014).

7. H. S. Choi, H. N. Han, and D. N. Lee, Met. Mater. Int. 23,
132 (2017).

8. F. J. Humphreys and M. Hatherly, Recrystallization and Related Annealing Phenomena, 1, Pergamon Press, Oxford (1995).

9. E. N. Borodin, A. E. Mayer, and P. N. Mayer, Proc. 13th International Conference on Fracture (eds S. Yu, X.-Q. Feng), Beijing, China (2013).

10. H. Liu, Y. Shen, J. Ma, P. Zheng, and L. Zhang, J. Mater. Eng. Perform. 25, 3599 (2016).

11. M. Jo, E. A. Choi, J. H. Ahn, Y. G. Son, K. Kim, J. Lee, S. Semboshi, and S. Z. Han, Korean J. Met. Mater. 57, 10 (2019).

12. S. J. Lee, H. S. Shin, E. A. Choi, J. H. Ahn, Y. Choi, S. Kim, J. Lee, and S. Z. Han, Korean J. Met. Mater. 58, 488 (2020).

13. H. Tohmyoh and Y. Matsudo, Appl. Phys. Express 8, 045503 (2015).

14. M. Hummelgård, R. Zhang, T. Carlberg, D. Vengust, D. Dvorsek, D. Mihailovic, and H. Olin, Nanotechnology 21, 165704 (2010).

15. G. Bakan, N. Khan, A. Cywar, K. Cil, M. Akbulut, A. Gokirmak, and H. Silva, J. Mater. Res. 26, 1061 (2011)

16. M. Yang, C. Feng, K. Gong, H. Wang, L. Wang, Q. Zhan, B. Li, J.-P. Wang, and G.-H. Yu, IEEE Trans. Magn. 49, 3660 (2013).

17. T. Sameshima, Y. Kaneko, and N. Andoh, J. Non-Cryst. Solids 299, 746 (2002).

18. R. Houssa, V. Franco, and A. Conde, J. Magn. Magn. Mater. 203, 199 (1999).

19. H. Tohmyoh and M. Ishihara, Appl. Phys. Express 6, 077302 (2013).

20. H. Tohmyoh, A. Fukuda, and Y. Kimura, J. Soc. Mater. Sci. Japan 68, 443 (2019).

21. C. Rudolf, R. Goswami, W. Kang, and J. Thomas, Acta. Mater. 209, 116776 (2021).

22. N. Inakazu, Y. Kaneno, and H. Inoue, Mater. Sci. Forum 157, 715 (1994)

23. J. Schamp, B. Verlinden, and F. V. Humbeeck, Scripta. Mater. 34, 1667 (1996).

24. P. N. Kalu, L. Brandao, F. Ortiz, O. Egungwu, and F. Ige, Scripta. Mater. 38, 1755 (1998).

25. H. Park and D. N. Lee, Mater. Sci. Forum 408, 637 (2002).

26. D. N. Lee, Met. Mater. 5, 401 (1999). 